\title{
A Novel Estimation Method of Wind Speed and Direction Based on GNSS/INS/ADS Integrated Navigation
}

\author{
Jingjuan Zhang, Hao Cong $(D$, and Xueyun Wang $(\mathbb{D}$ \\ School of Instrument Science and Opto-Electronics Engineering, Beihang University, Beijing 100191, China \\ Correspondence should be addressed to Xueyun Wang; wangxueyun@buaa.edu.cn
}

Received 17 July 2021; Revised 27 October 2021; Accepted 6 December 2021; Published 20 December 2021

Academic Editor: Chen Yang

Copyright (c) 2021 Jingjuan Zhang et al. This is an open access article distributed under the Creative Commons Attribution License, which permits unrestricted use, distribution, and reproduction in any medium, provided the original work is properly cited.

\begin{abstract}
Arriving on time is of great importance for flight management and passenger experience. One of the essential factors that impacts on-time arrival is the wind condition. Accurate information of wind speed and direction around the fuselage helps to improve the performance of on-time arrival and four-dimensional trajectory (4DT) planning. To determine accurate wind information in real-time, a novel airborne estimation method of wind speed and direction is proposed in this paper. Inertial Navigation System (INS), Global Satellite Navigation System (GNSS), and Air Data System (ADS) are fused in an Unscented Kalman Filter (UKF), which provides great accuracy and robustness in nonlinearity conditions. The dynamic models of wind are established, and implementations of the UKF are detailed. Finally, simulations are designed and the effectiveness of the proposed method is verified through the comparison with the traditional direct measurement method. Results demonstrate that the accuracy of wind speed and direction obtained by our method is nearly two times higher than the traditional direct measurement method.
\end{abstract}

\section{Introduction}

The estimation of instantaneous wind speed and direction at the location of the aircraft can be a significant problem due to the inevitable presence of wind in the flying. This problem is particularly important in four-dimensional trajectory (4DT) planning $[1,2]$. Four-dimensional trajectory planning is aimed at conducting trajectory planning in four-dimensional space $[3,4]$. The resulting flight trajectory includes all the three-dimensional positions where the aircraft is flying and the flight time when it is in that position, which means both the three-dimensional coordinates of the trajectory and the time to reach the threedimensional coordinate point are planned. Since wind speed and direction can have a great impact on the time dimension of four-dimensional trajectory planning, accurate real-time wind information is needed in $4 \mathrm{DT}$. Besides, the ambient wind speed and direction are also very useful information for various objectives such as flight control [5], micro aerial vehicles [6], atmospheric energy harvesting [7-9], air traffic control [10], aerial refueling [11], and collision avoidance. A popular approach to the wind estimation problem involves applying the aircraft dynamic model to predict the information of wind through Kalman filter $[12,13]$.

A problem with the existing work using Extended Kalman Filter (EKF) [14-17] for wind estimation [18] is that the wind dynamic model is nonlinear so the linearization accuracy of EKF may not be enough or even diffuse. Lefas developed a simple filter for wind estimation using magnetic heading, true air speed, and radar measurements; however, the data transmitted through the air-ground data link of the radar system can result in wildly erroneous measurements [10]. Langelaan et al. conducted a thorough simulation research on a method of directly estimating wind field; however, the measurement error of wind speed increases with the increase of airspeed [1]. Cho et al. proposed a 
method of horizontal wind estimation based on the EKF, which combines simulation and experimental data; however, it is usually not feasible in practical application that the aircraft needs to make banking turns or circle maneuvers, especially for civilian flights [19]. The horizontal wind speed and direction are predicted by the assumption of random moving noise, and then, these states are adjusted by the wind triangle comparison of air speed and ground speed provided by GPS [20, 21]. There is also some work in wind estimation using the Unscented Kalman Filter (UKF), though this work is limited in assuming a known a priori wind direction [22]. Taylor presented a simulation study of parameter estimation techniques for air data calibration and wind estimation [23]. This method assumes that the inertial velocities and Euler angles are accurate, that the calibration models are correct, and that the steady-state component of wind is constant throughout the maneuver. Liu et al. [24] comprehensively evaluated the sideslip angle estimation methods of vehicles in a comparative study. The results show that under the dynamic model, the UKF has higher performance than EKF to a certain extent. To overcome the time-varying and complexity of environmental noise information in practical application, Wang et al. [25] derived an AEKF method from a maximum-likelihood estimation for rolling state estimation. The results show that AEKF has better performance and feasibility than EKF. Under the condition of multisensor measurement, Ding et al. [26] proposed a weighted measurement fusion Kalman estimator based on centralized fusion to estimate the longitudinal vehicle speed. Through the combination of multiple sensor signals, three virtual sensors are formed, each virtual sensor generates a corresponding speed information, and the speed information in a long time is obtained by weighting coefficient estimation. It has high precision and reliability. This shows that the combination of data fusion and Kalman filter is of great significance.

The work introduced herein is to deduce the estimation formulas of three-dimensional wind speed and direction based on the measurements from airborne Global Satellite Navigation System (GNSS), the output results of Inertial Navigation System (INS), and the information of airspeed, angle of attack, and sideslip angle provided by an Air Data System (ADS). The work also extends Cho's work including vertical wind and wind direction, as well as angle of attack and sideslip information. In addition, the three-dimensional position is also provided as measurements, which is of great significance to improve the accuracy of wind estimation. The contribution of this work is that it provides an innovative method based on UKF for real-time and accurate estimation of wind field information around aircraft, as well as navigation, position, and flow angle information.

The organization of this paper proceeds as follows. Section 2 describes the aircraft dynamic equations. Section 3 introduces the Unscented Kalman Filter used in wind speed and direction estimation in this paper. Section 4 presents various simulations and their results. Finally, Section 5 presents the concluding remarks.

\section{Problem Formulations}

The estimation algorithm uses information from an Air Data System (ADS), Global Satellite Navigation System (GNSS), and Inertial Navigation System (INS) to estimate the threedimensional components of wind speed and direction.

2.1. Introduction of Coordinates. First, the coordinates that are used in the paper are defined.

$O_{n}-X_{n} Y_{n} Z_{n}$ denotes the navigation frame which coincides with the geographic frame $\left(O_{g}-X_{g} Y_{g} Z_{g}\right)$, north east and down (NED).

$O_{b}-X_{b} Y_{b} Z_{b}$ denotes the aircraft body coordinate frame. $O_{b}$ is at the center of gravity, $X_{b}$ is in the plane of symmetry of the aircraft and parallel to the design axis of the aircraft and points to the nose, $Y_{b}$ is perpendicular to the plane of symmetry of the aircraft and points to the right of the fuselage, and $Z_{b}$ is in the plane of symmetry of the aircraft, perpendicular to the $X_{b}$ and pointing below the fuselage. The rotation from NED to the aircraft body coordinate system is defined by Euler angles, as shown in Figure 1.

$O_{w}-X_{w} Y_{w} Z_{w}$ denotes the wind coordinate frame. $O_{w}$ is at the center of gravity and fixed connection with aircraft body; $X_{w}$ is pointing at the direction of airspeed $V_{a} ; Z_{w}$ is in the plane of symmetry of the aircraft, perpendicular to the $X_{w}$ and pointing below the fuselage; and $Y_{b}$ is defined by the right-hand rule. Rotation from the aircraft body coordinate frame to the wind coordinate frame is defined by the angle of attack $\alpha$ and sideslip $\beta$, as shown in Figure 2 .

2.2. Dynamic Equations. The following quantities are studied in this paper:

(1) The forward, rightward, and downward airspeed components $u, v$, and $w$, respectively

(2) The roll $\phi$, pitch $\theta$, and yaw $\psi$ of the Euler attitude angles

(3) The northward, eastward, and downward wind velocity components $w_{x}, w_{y}$, and $w_{z}$

(4) The latitude $L$, the longitude $\lambda$, and the altitude $H$ of the aircraft

(5) The pitot tube velocity $V_{\text {pitot }}$, angle of attack $\alpha$, and sideslip angle $\beta$ derived from the Air Data System

(6) The northward, eastward, and downward velocity (ground speed) $\left(V_{x m} V_{y m} V_{z m}\right)$ and positions $\left(\begin{array}{lll}L_{m} & \lambda_{m} & H_{m}\end{array}\right)$ provided by the GNSS

(7) The accelerations $\left(\begin{array}{lll}a_{x} & a_{y} & a_{z}\end{array}\right)$ and angular velocity $\left(\begin{array}{lll}p & q & r\end{array}\right)$ derived from the Inertial Measurement Unit (IMU).

Firstly, based on the flight dynamics and the assumption that the plane is a rigid body, the motion equations of the aircraft are established as follows.

The conversion from the aircraft body coordinate frame to the geographic coordinate system is defined by the Direction Cosine Matrix (DCM), which is derived 


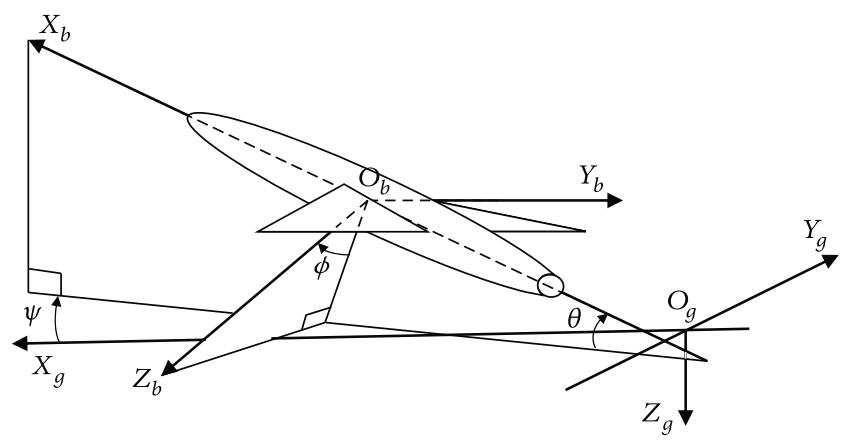

FIGURE 1: Relationship between the aircraft body coordinate frame and the geographic system.

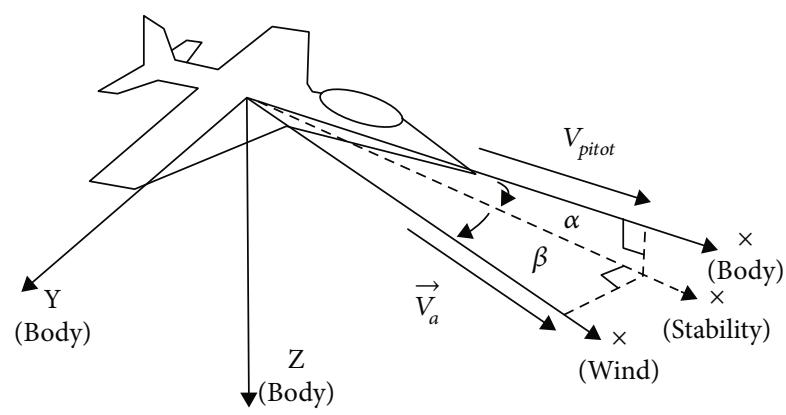

FIGURE 2: Relationship between the wind coordinate frame and the aircraft body coordinate frame.

from the continuous rotation of roll $\phi$, pitch $\theta$, and yaw $\psi$ of the aircraft.

$$
\begin{aligned}
C_{b}^{n}= & \operatorname{DCM}(\phi, \theta, \psi) \\
= & {\left[\begin{array}{ccc}
\cos \psi & -\sin \psi & 0 \\
\sin \psi & \cos \psi & 0 \\
0 & 0 & 1
\end{array}\right]\left[\begin{array}{ccc}
\cos \theta & 0 & \sin \theta \\
0 & 1 & 0 \\
-\sin \theta & 0 & \cos \theta
\end{array}\right] } \\
& \cdot\left[\begin{array}{ccc}
1 & 0 & 0 \\
0 & \cos \phi & -\sin \phi \\
0 & \sin \phi & \cos \phi
\end{array}\right] .
\end{aligned}
$$

The following force equations can be obtained by decomposing the total aerodynamic forces and the thrusts $\left(F_{x}, F_{y}, F_{z}\right)$ into the aircraft body coordinate system and then decomposing the gravity into the aircraft body coordinate system, too:

$$
\left\{\begin{array}{l}
\dot{u}=v r-w q-g \sin \theta+\frac{F_{x}}{m}, \\
\dot{v}=-u r+w p+g \cos \theta \sin \phi+\frac{F_{y}}{m}, \\
\dot{w}=u q-v p+g \cos \theta \cos \phi+\frac{F_{z}}{m},
\end{array}\right.
$$

where $m$ is the total mass of the aircraft which is assumed to be a constant. The relationship between the attitude rate $\left(\begin{array}{lll}\dot{\phi} & \dot{\theta} & \dot{\psi}\end{array}\right)$ and the three angular velocity components $\left(\begin{array}{lll}p & q & r\end{array}\right)$ in the body coordinate system can be described by the dynamic equations as follows [27]:

$$
\left\{\begin{array}{l}
\dot{\phi}=p+(r \cos \phi+q \sin \phi) \tan \theta, \\
\dot{\theta}=q \cos \phi-r \sin \phi \\
\dot{\psi}=(r \cos \phi+q \sin \phi) \sec \theta .
\end{array}\right.
$$

According to the characteristic of randomness, the state model of wind speed is set as a random walk process [19].

The dynamics for the position states are then given by groundspeeds of the aircraft:

$$
\left\{\begin{array}{l}
\dot{L}=\frac{V_{x}}{R_{m}+H} \\
\dot{\lambda}=\frac{V_{y}}{R_{n}+H} \sec L \\
\dot{H}=V_{z}
\end{array}\right.
$$

where $R_{m}=\mathrm{R}_{e}\left(1-2 e+3 e \sin ^{2} L\right), R_{n}=R_{e}\left(1+e \sin ^{2} L\right)$, and $R_{e}=6378393 \mathrm{~m}$, and $e=1 / 297.3$ is the oblation of rotating ellipsoid. ( $\left.\begin{array}{llll}V_{x} & V_{y} & V_{z}\end{array}\right)$ are groundspeeds of the aircraft in navigation coordinates. They can be correlated with the wind speed in geographic coordinates and the airspeed in the aircraft body coordinate through the Direction Cosine Matrix as follows:

$$
\left[\begin{array}{c}
V_{x} \\
V_{y} \\
V_{z}
\end{array}\right]=C_{b}^{n}\left[\begin{array}{l}
u \\
v \\
w
\end{array}\right]+\left[\begin{array}{c}
w_{x} \\
w_{y} \\
w_{z}
\end{array}\right] .
$$

Secondly, the mathematical models related with pitot speed, angle of attack, and sideslip angle are presented. The pitot speed $V_{\text {pitot }}$ is calculated using the dynamic pressure measured from a sensor connected to a pitot tube. The calculation formula is based on Bernoulli equation, and it yields

$$
V_{\text {pitot }}^{2}=K \frac{2 \Delta P}{\rho}=u^{2}+v^{2}+w^{2}
$$

where $\Delta P$ is the dynamic pressure, $\rho$ is the air density, and $K$ is the correction factor [28].

Attack angle $\alpha$ and sideslip angle $\beta$ can be derived from the airspeed components in the body coordinate system [29]:

$$
\begin{aligned}
& \alpha=\arctan \frac{w}{u} \\
& \beta=\arcsin \left(\frac{v}{\sqrt{u^{2}+v^{2}+w^{2}}}\right) .
\end{aligned}
$$




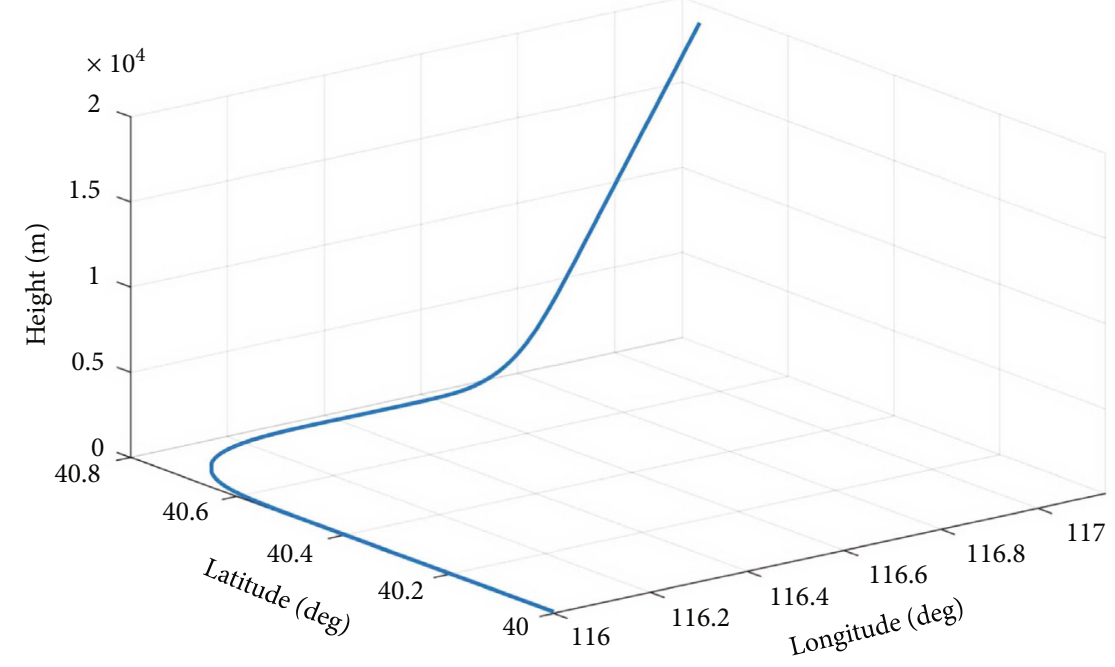

FIGURE 3: Flight path.

Through the angle of attack, the sideslip angle, and $V_{\text {pitot}}$, airspeed $V_{a}$ in navigation coordinates can be expressed as

$$
V_{a}=C_{b}^{n}\left[\begin{array}{c}
\cos \alpha \cos \beta \\
\sin \beta \\
\sin \alpha \cos \beta
\end{array}\right] V_{\text {pitot }} .
$$

Therefore, the wind speed $w_{x}, w_{y}$, and $w_{z}$ can be computed directly from the wind speed triangle as [30]

$$
\left[\begin{array}{l}
w_{x} \\
w_{y} \\
w_{z}
\end{array}\right]=\left[\begin{array}{c}
V_{x m} \\
V_{y m} \\
V_{z m}
\end{array}\right]-C_{b}^{n}\left[\begin{array}{c}
\cos \alpha \cos \beta \\
\sin \beta \\
\sin \alpha \cos \beta
\end{array}\right] V_{\text {pitot }} .
$$

This method is traditionally used for wind information, and it is compared in the Section 4 for the better accuracy of our method.

Besides of speed, the information of the wind field around the aircraft also includes the wind direction, namely, the wind azimuth and the wind pitch. The angle between the wind speed and the north is defined as the wind azimuth:

$$
w_{a z}=\arctan \frac{w_{z}}{w_{x}} .
$$

The angle between the wind speed and the horizontal plane is defined as the wind pitch:

$$
w_{\mathrm{an}}=\arctan \frac{w_{y}}{\sqrt{w_{x}^{2}+w_{z}^{2}}} .
$$

Their accuracy is also compared in the simulations.
TABLE 1: Standard deviations of measurement noise.

\begin{tabular}{lcc}
\hline Parameter & Variable & Noise standard deviation \\
\hline Position (GNSS) & $L_{m}, \lambda_{m}, H_{m}$ & $1 \mathrm{~m}$ \\
Ground speed (GNSS) & $V_{x}, V_{y}, V_{z}$ & $0.2 \mathrm{~m} / \mathrm{s}$ \\
Acceleration (IMU) & $a_{x}, a_{y}, a_{z}$ & $0.001 \mathrm{~g}$ \\
Angular rate (IMU) & $p, q, r$ & $0.01^{\circ} / \mathrm{h}$ \\
Airspeed & $V_{a}$ & $0.5 \mathrm{~m} / \mathrm{s}$ \\
Angle of attack & $\alpha$ & $0.1^{\circ}$ \\
Sideslip angle & $\beta$ & $0.1^{\circ}$ \\
\hline
\end{tabular}

\section{Estimation Method of Wind Speed and Direction}

Since the GNSS/INS/ADS integrated navigation system possesses nonlinear characteristics, nonlinear estimation algorithms such as EKF or UKF are needed. Because EKF is a first-order approximation of nonlinear system, while UKF has at least second-order approximation accuracy and Jacobian matrices are unnecessary, which reduce the computation complexity, UKF is adopted to estimate wind speed and direction online in this study. The research of Liu et al. [24] and Ding et al. [26] also trues this point.

According to the dynamic equations detailed in Section 2, the state vector $X$ consists the following elements: the airspeeds $\left[\begin{array}{lll}u & v & w\end{array}\right]^{T}$ in the body coordinate frame, Euler attitude angles $\left[\begin{array}{lll}\phi & \theta & \psi\end{array}\right]^{T}$, three-axis wind speed $\left[\begin{array}{lll}w_{x} & w_{y} & w_{z}\end{array}\right]^{T}$, and three-dimensional position $\left[\begin{array}{lll}L & \lambda & H\end{array}\right]^{T}$. The input vector $U$ consists of accelerations and angular rates obtained through IMU. The groundspeed and position measured by GNSS, airspeed, angle of attack, and sideslip angle provided 

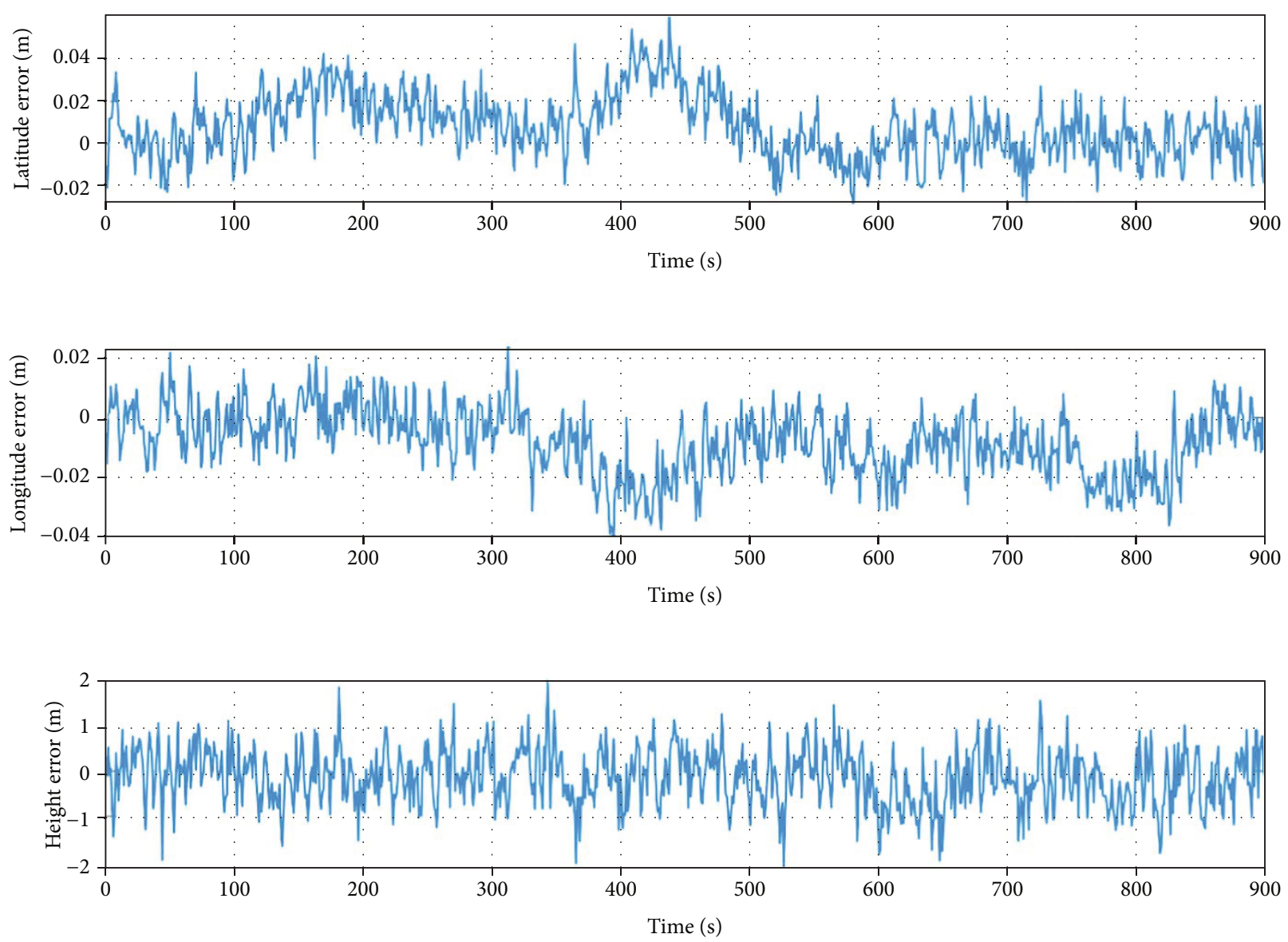

FIGURE 4: Position error obtained by integrated navigation.

by the ADS are adopted as the measurements $Z$ :

$$
\begin{aligned}
X & =\left[\begin{array}{llllllllllll}
u & v & w & \phi & \theta & \psi & w_{x} & w_{y} & w_{z} & L & \lambda & H
\end{array}\right]^{T}, \\
U & =\left[\begin{array}{lllllll}
a_{x} & a_{y} & a_{z} & p & q & r
\end{array}\right]^{T}, \\
Z & =\left[\begin{array}{lllllllll}
V_{x m} & V_{y m} & V_{z m} & V_{\text {pitot }} & \alpha & \beta & L_{m} & \lambda_{m} & H_{m}
\end{array}\right]^{T} .
\end{aligned}
$$

The state equation of the UKF is established as follows:

$$
X_{k}=f\left(X_{k-1}, u_{k-1}\right)+W_{k-1},
$$

where $f$ is the nonlinear vector function detailed in equations (2), (3), and (4) and $X_{k}$ and $X_{k-1}$ are the state vectors at $k$ and $k-1$ moment, respectively. $W_{k-1}$ is the zero-mean Gaussian process noise vector.

The measurement equation is established as follows:

$$
Z_{k}=h\left(X_{k}\right)+V_{k}
$$

where $h$ is a nonlinear observation function detailed in equations (5), (6), (7), and (8). $V_{k}$ is the zero-mean Gaussian measurement noise vector.

The UKF algorithms are as follows.
First, select the initial filtering values:

$$
\begin{gathered}
\widehat{X}_{0}=E X_{0}, \\
P_{0}=E\left[\left(X_{0}-\widehat{X}_{0}\right)\left(X_{0}-X \wedge_{0}\right)^{T}\right],
\end{gathered}
$$

where $E$ is the mathematical expectation, $X_{0}$ is the initial value of the state vector, $\widehat{X}_{0}$ is the mean value of the initial value of the state vector, and $P_{0}$ is the covariance matrix of the initial value of the state vector.

Second, calculate the sigma sample points at $k-1$ moment:

$\tilde{\chi}_{k-1}^{(0)}=\widehat{X}_{k-1}$

$\tilde{\chi}_{k-1}^{(i)}=\widehat{X}_{k-1}+\left(\sqrt{(n+\lambda) P_{k-1}}\right)_{(i)}, \quad i=1,2, \cdots, n$,

$\tilde{\chi}_{k-1}^{(i)}=\widehat{X}_{k-1}-\left(\sqrt{(n+\lambda) P_{k-1}}\right)_{(i-n)}, \quad i=n+1, n+2, \cdots 2 n$,

where $n$ is the state dimension and $\lambda=\alpha^{2}(n+\kappa)-n$, $\alpha \in\left[10^{-4}, 1\right], \kappa=3-n$. 

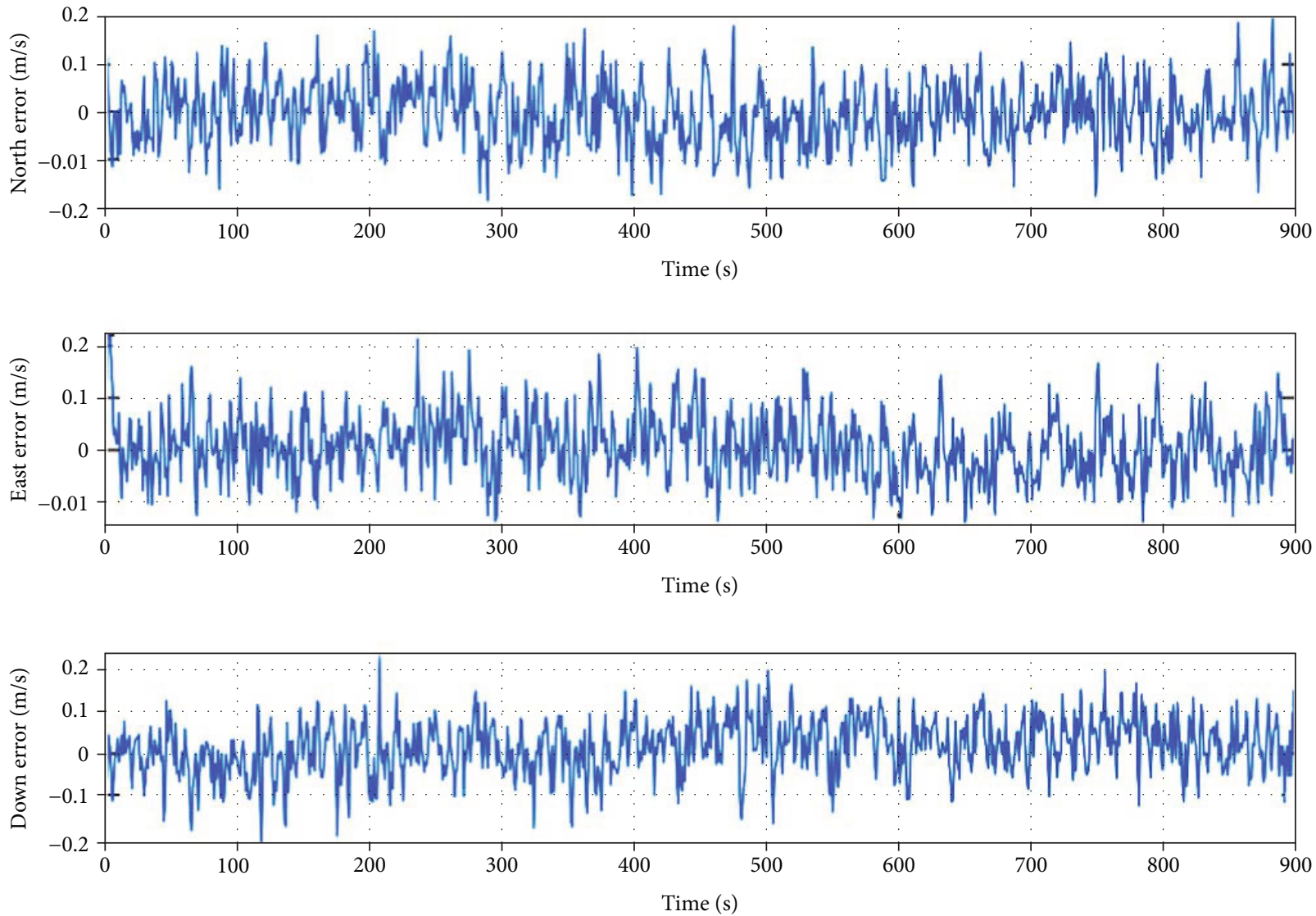

FIGURE 5: Speed error obtained by integrated navigation.

Third, determine the weight:

$$
\begin{aligned}
W_{0}^{(m)} & =\frac{\lambda}{n+\lambda}, \\
W_{0}^{(c)} & =\frac{\lambda}{n+\lambda}+1-\alpha^{2}+\beta, \\
W_{i}^{(m)} & =W_{i}^{(c)}=\frac{1}{2(n+\lambda)}, \quad i=1,2, \cdots, 2 n,
\end{aligned}
$$

where $W_{0}^{(m)}$ and $W_{j}^{(m)}$ are the weights of the state vector of the $i$ th sigma point, $W_{0}^{(c)}$ and $W_{i}^{(c)}$ are the weights of the covariance matrix of the state vector of the $i$ th sigma point, and $\beta$ is the state distribution parameter. For Gaussian white noise, $\beta=2$.

Fourth, calculate the one-step prediction model value of $k$ moment:

$$
\begin{aligned}
\chi_{k / k-1}^{(i)} & =f\left[\tilde{\chi}_{k-1}^{(i)}, u_{k-1}\right], \quad i=0,1,2, \cdots, 2 n, \\
\widehat{X}_{k / k-1} & =\sum_{i=0}^{2 n} W_{i}^{(m)} \chi_{k / k-1}^{(i)}, \\
P_{k / k-1} & =\sum_{i=0}^{2 n} W_{i}^{(c)}\left[\chi_{k / k-1}^{(i)}-\widehat{X}_{k / k-1}\right]\left[\chi_{k / k-1}^{(i)}-X \wedge_{k / k-1}\right]^{T}+Q_{k-1} .
\end{aligned}
$$

$\widehat{X}_{k / k-1}$ is the prediction state vector, $P_{k / k-1}$ is the covariance matrix of the prediction state vector, and $Q_{k-1}$ is the state vector noise matrix in the last moment.

Fifth, calculate the one-step prediction sample point of $k$ moment:

$$
\begin{aligned}
& \chi_{k / k-1}^{(0)}=\widehat{X}_{k / k-1}, \\
& \chi_{k / k-1}^{(i)}=\widehat{X}_{k / k-1}+\left(\sqrt{(n+\lambda) P_{k / k-1}}\right)_{(i)}, \quad i=1,2, \cdots, n, \\
& \chi_{k / k-1}^{(i)}=\widehat{X}_{k / k-1}-\left(\sqrt{(n+\lambda) P_{k / k-1}}\right)_{(i-n)}, \quad i=n+1, n+2, \cdots 2 n .
\end{aligned}
$$

Sixth is measurement update:

$$
\begin{aligned}
Z_{k / k-1}^{(i)} & =h\left[\chi_{k / k-1}^{(i)}\right], \quad i=0,1,2, \cdots, n, \\
\widehat{Z}_{k / k-1} & =\sum_{i=0}^{2 n} W_{i}^{(m)} Z_{k / k-1}^{(i)}, \\
P_{(Z Z)_{k / k-1}} & =\sum_{i=0}^{2 n} W_{i}^{(i)}\left[Z_{k / k-1}^{(i)}-\widehat{Z}_{k / k-1}\right]\left[Z_{k / k-1}^{(i)}-Z \wedge_{k / k-1}\right]^{T}+R_{k}, \\
P_{(X Z)_{k / k-1}} & =\sum_{i=0}^{2 n} W_{i}^{(c)}\left[\chi_{k / k-1}^{(i)}-\widehat{X}_{k / k-1}\right]\left[Z_{k / k-1}^{(i)}-Z \wedge_{k / k-1}\right]^{T},
\end{aligned}
$$



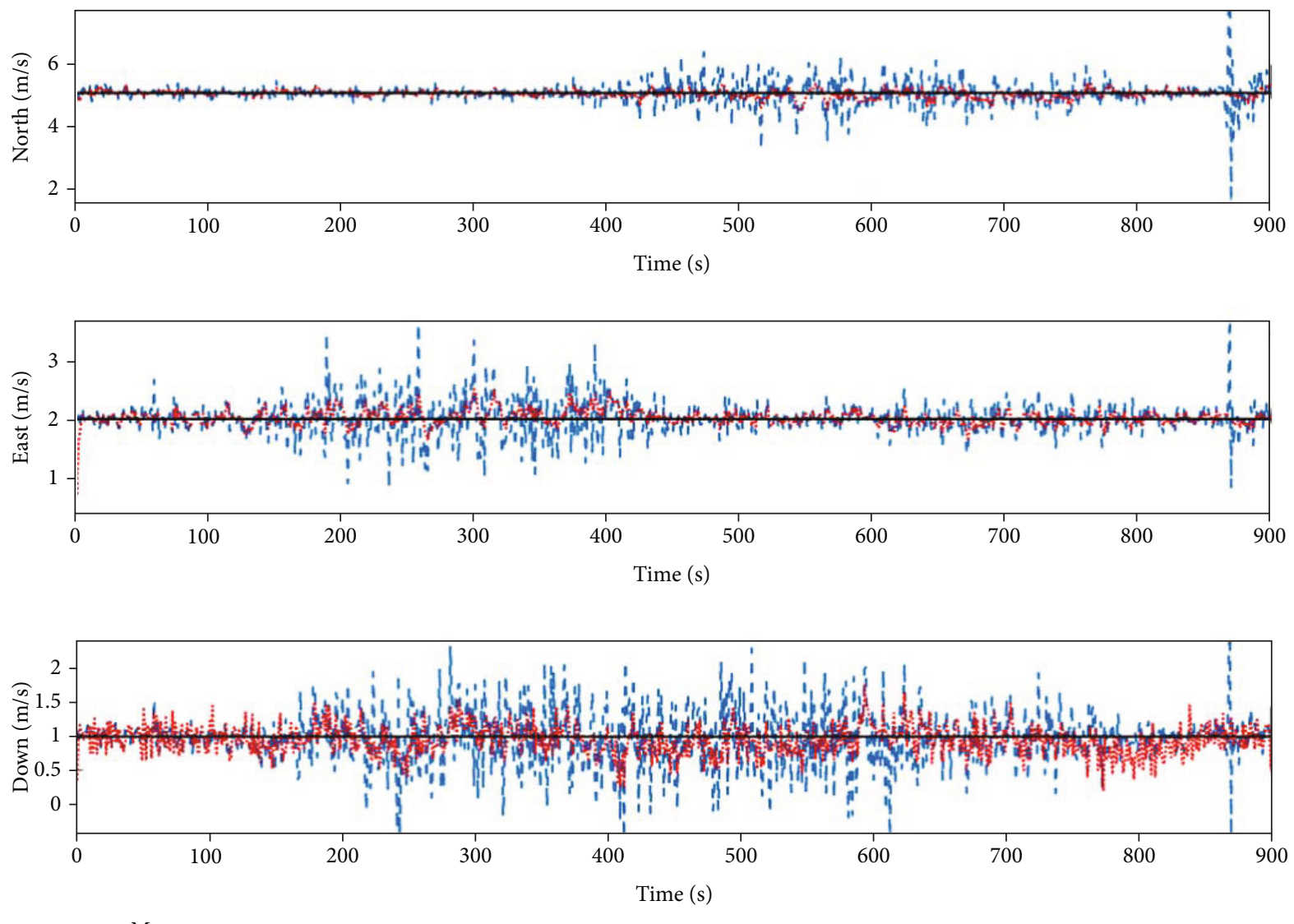

- - - Measurements

Estimates

— Truth

Figure 6: Wind speed measurements, estimates, and true values.

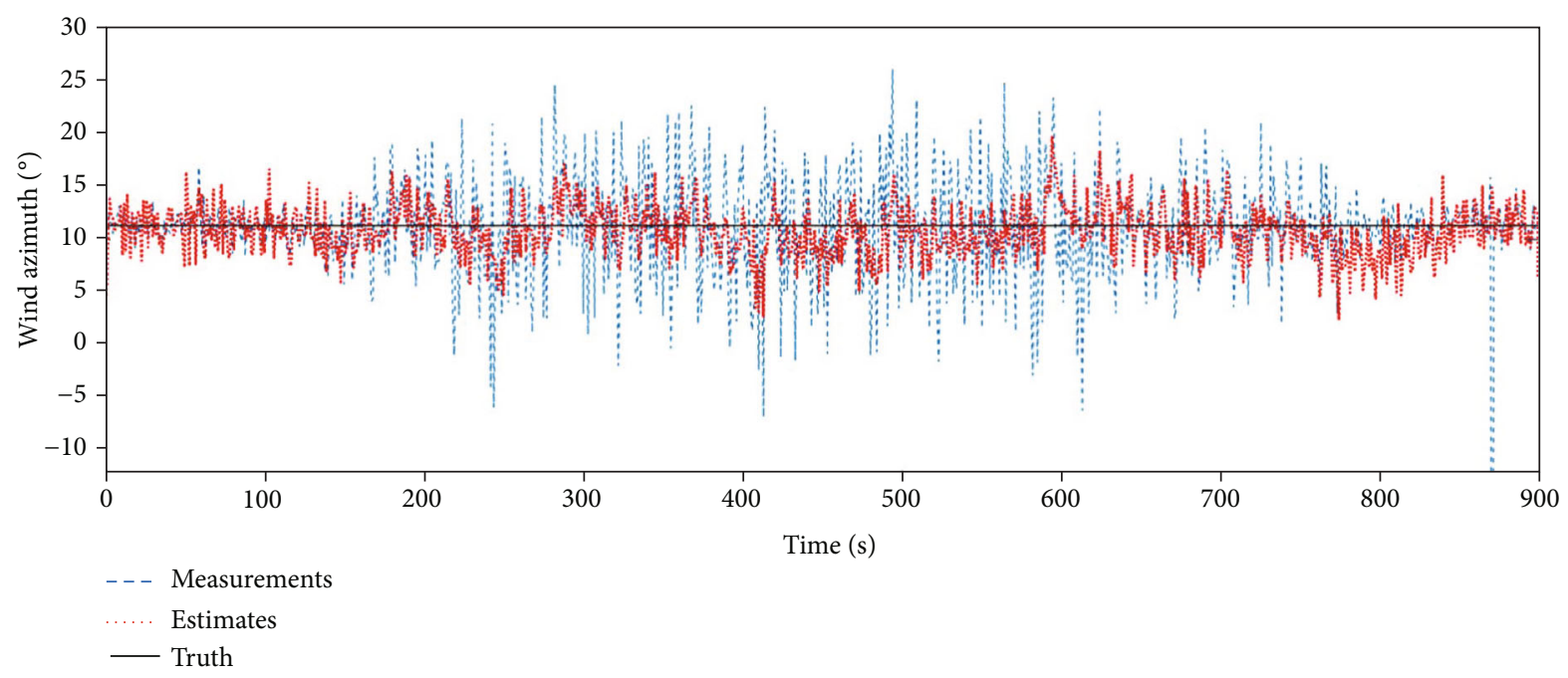

Figure 7: Wind azimuth measurements, estimates, and true values. 


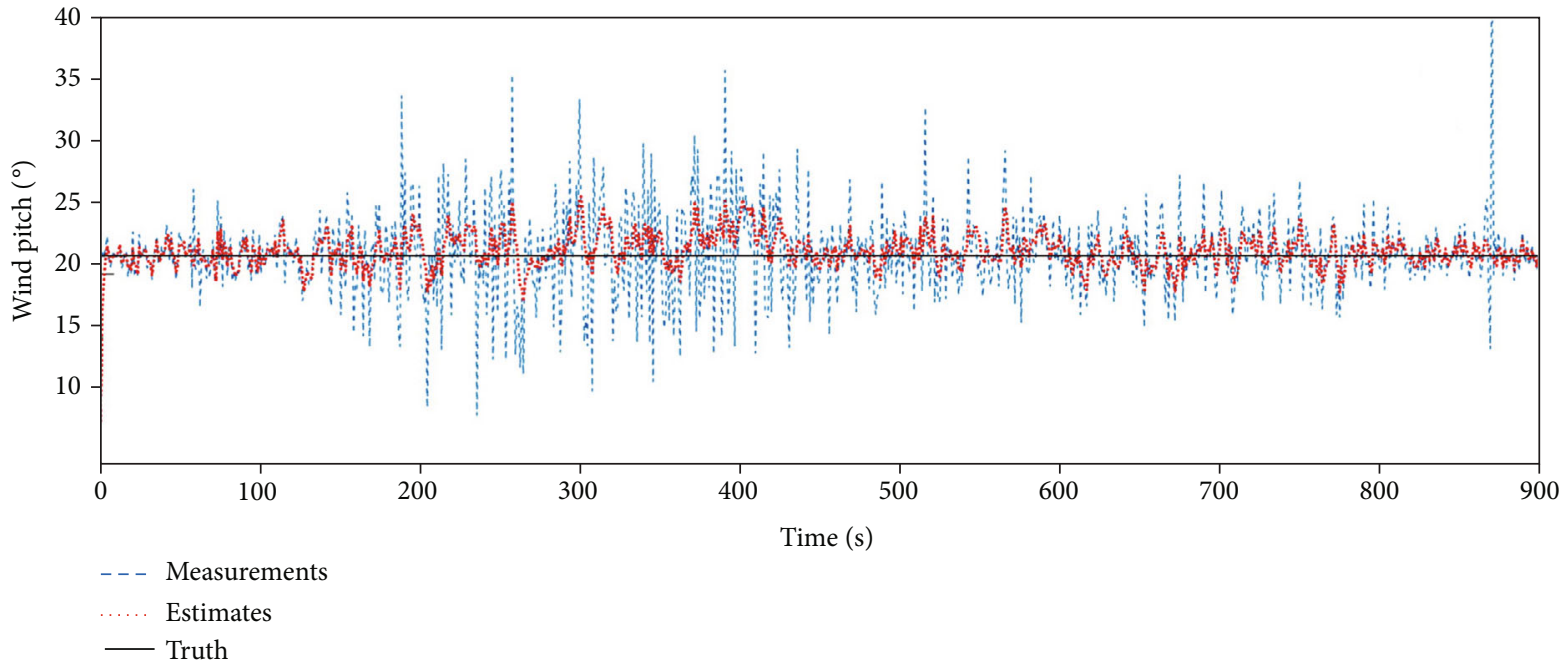

FiguRE 8: Wind pitch measurements, estimates, and true values.

TABLE 2: Standard deviation of estimated and measured wind speed for constant wind.

\begin{tabular}{|c|c|c|c|c|c|c|}
\hline \multirow[b]{2}{*}{$\begin{array}{l}\text { Speed: } \mathrm{m} / \mathrm{s} \\
\text { Angle: }\end{array}$} & \multicolumn{2}{|c|}{ Group 1} & \multicolumn{2}{|c|}{ Group 2} & \multicolumn{2}{|c|}{ Group 3} \\
\hline & $\begin{array}{l}\text { Standard deviation } \\
\text { of measurements }\end{array}$ & $\begin{array}{c}\text { Standard } \\
\text { deviation of } \\
\text { estimations }\end{array}$ & $\begin{array}{l}\text { Standard deviation } \\
\text { of measurements }\end{array}$ & $\begin{array}{c}\text { Standard } \\
\text { deviation of } \\
\text { estimations }\end{array}$ & $\begin{array}{l}\text { Standard deviation } \\
\text { of measurements }\end{array}$ & $\begin{array}{c}\text { Standard } \\
\text { deviation of } \\
\text { estimations }\end{array}$ \\
\hline North & 0.33 & 0.12 & 0.43 & 0.12 & 0.53 & 0.11 \\
\hline East & 0.33 & 0.13 & 0.31 & 0.13 & 0.31 & 0.12 \\
\hline Down & 0.38 & 0.13 & 0.42 & 0.16 & 0.44 & 0.15 \\
\hline Resultant & 0.33 & 0.12 & 0.43 & 0.13 & 0.54 & 0.12 \\
\hline Azimuth & 4.78 & 1.69 & 4.70 & 1.83 & 4.70 & 1.73 \\
\hline Pitch & 3.66 & 1.57 & 3.41 & 1.34 & 3.28 & 1.32 \\
\hline
\end{tabular}

where $\widehat{Z}_{k / k-1}$ is the prediction observation vector, $P_{(z z)_{k / k-1}}$ is the covariance matrix of prediction vector and observation vector, $P_{(X Z)_{k / k-1}}$ is the covariance matrix of prediction observation and state vector, and $R_{k}$ is the observation noise matrix.

Seventh is filter update:

$$
\begin{aligned}
& K_{k}=P_{(X Z)_{k / k-1}} P_{(Z Z)_{k / k-1},}^{-1} \\
& \widehat{X}_{k}=\widehat{X}_{k / k-1}+K_{k}\left[Z_{k}-\widehat{Z}_{k / k-1}\right], \\
& P_{k}=P_{k / k-1}-K_{k} P_{(Z Z)_{k / k-1}} K_{k}^{T},
\end{aligned}
$$

where $K_{k}$ is the gain matrix, $\widehat{X}_{k}$ is the estimated state vector, and $P_{k}$ is the covariance matrix of the estimated state vector.

\section{Simulation Verifications}

In order to evaluate the feasibility and effectiveness of the estimation method for wind speed and direction, various simulations were carried out. The simulated trajectory lasts $900 \mathrm{~s}$, and the three-dimension flight path is shown in Figure 3.

In the simulation experiment, the sampling rate of the IMU is $100 \mathrm{~Hz}$ and the frequency of integrated navigation is $1 \mathrm{~Hz}$. The measurement noise is assumed to be Gaussian white noise, and the standard deviations are shown in Table 1.

The position error obtained by the integrated navigation is shown in Figure 4. The standard deviations of latitude, longitude, and height errors are $0.014 \mathrm{~m}, 0.011 \mathrm{~m}$, and $0.65 \mathrm{~m}$, respectively.

The speed error obtained by integrated navigation is shown in Figure 5. The standard deviations of the north, east, and down speed errors are $0.070 \mathrm{~m} / \mathrm{s}, 0.065 \mathrm{~m} / \mathrm{s}$, and $0.064 \mathrm{~m} / \mathrm{s}$, respectively.

In the first simulation, wind speed and direction are set to constants. The results of the proposed estimation method based on UKF estimation are depicted in Figure 6. In the figure, the Measurements refer to raw wind speed information, which is calculated according to equation (10). The Estimates refer to the wind speed estimated by UKF, and Truth is the reference wind speed. As shown in Figure 6, the accuracy of wind speed obtained by the proposed method in this paper is much higher than that of the raw wind speed. The standard deviations of the wind speed error of the proposed method are $0.12 \mathrm{~m} / \mathrm{s}, 0.14 \mathrm{~m} / \mathrm{s}$, and $0.13 \mathrm{~m} / \mathrm{s}$, respectively, while they are $0.33 \mathrm{~m} / \mathrm{s}, 0.34 \mathrm{~m} / \mathrm{s}$, and $0.38 \mathrm{~m} / \mathrm{s}$ for raw wind speed scenario.

After the wind speeds are obtained, the corresponding wind azimuth (as shown in Figure 7) and pitch (as shown 

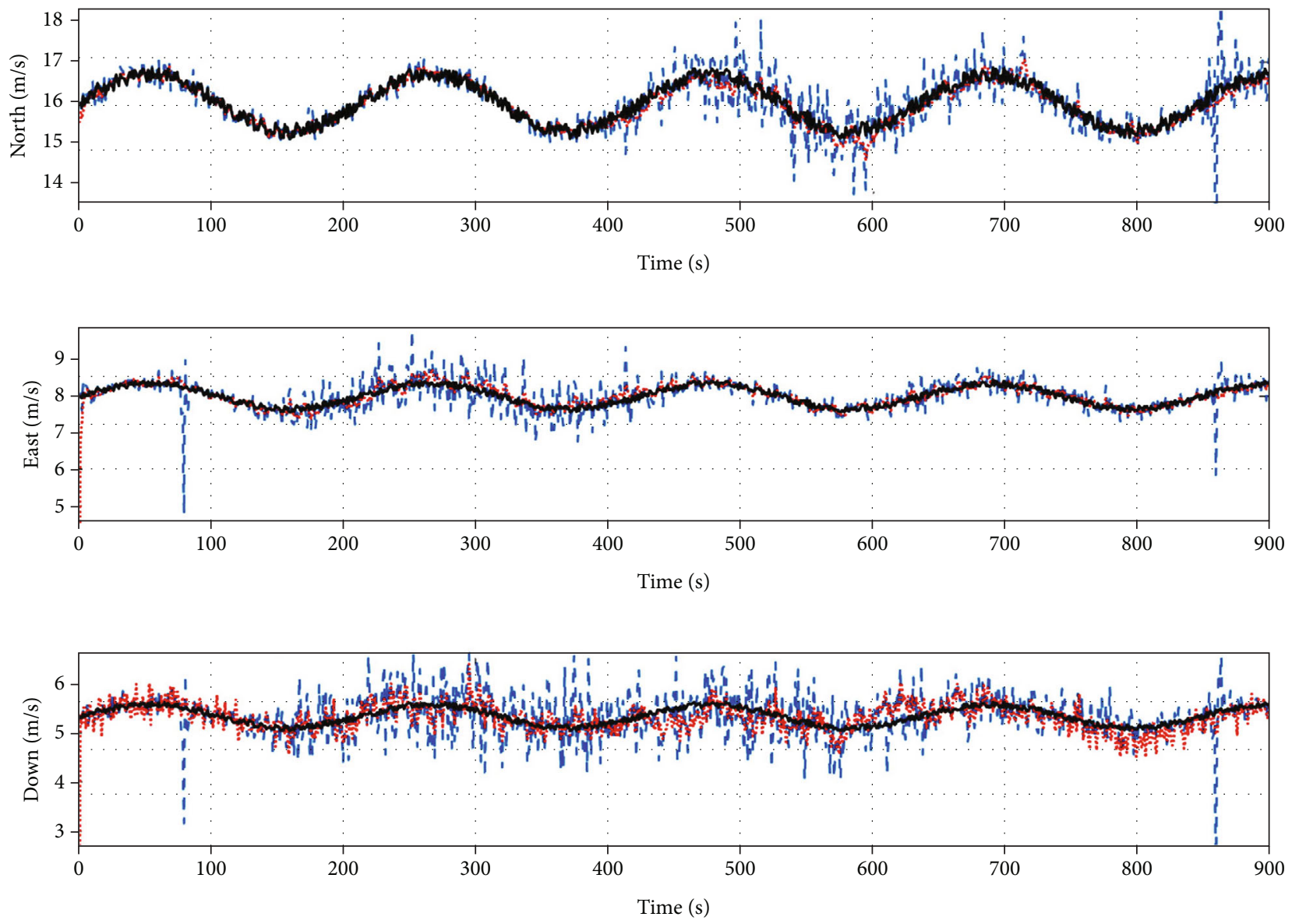

--- Measurements

Estimates

— Truth

Figure 9: Wind speed measurements, estimates, and true values.

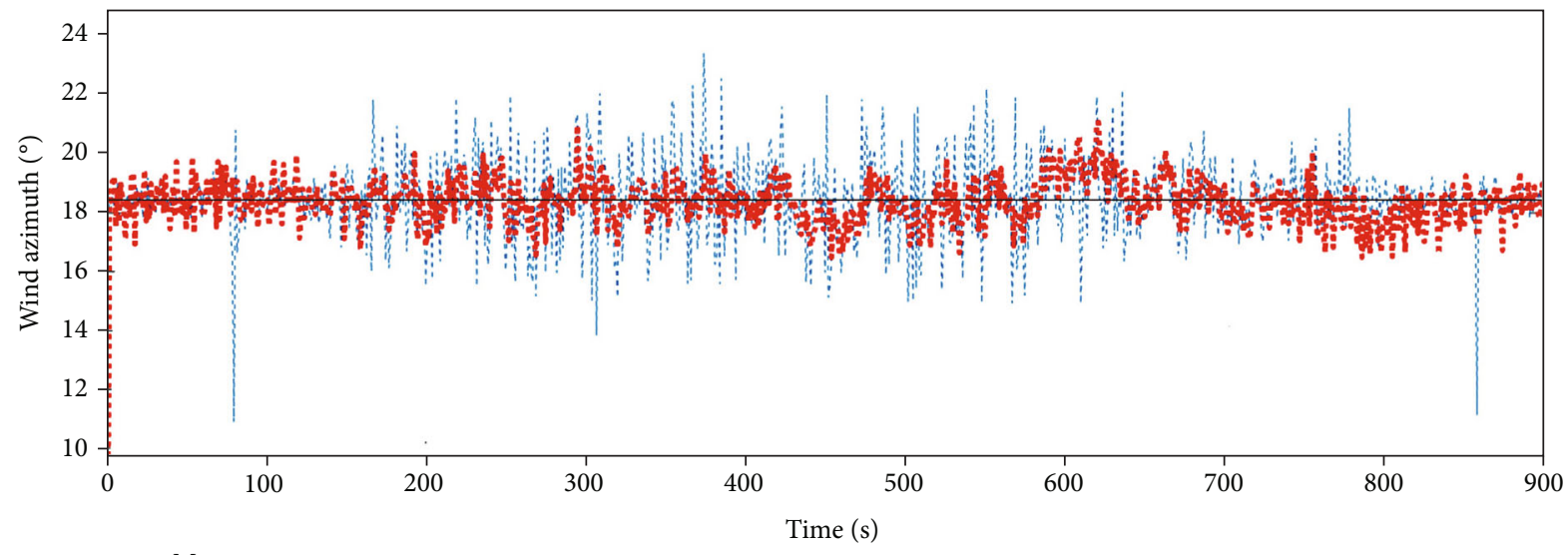

--- Measurements

Estimates

- Truth

Figure 10: Wind azimuth measurements, estimates, and true values. 


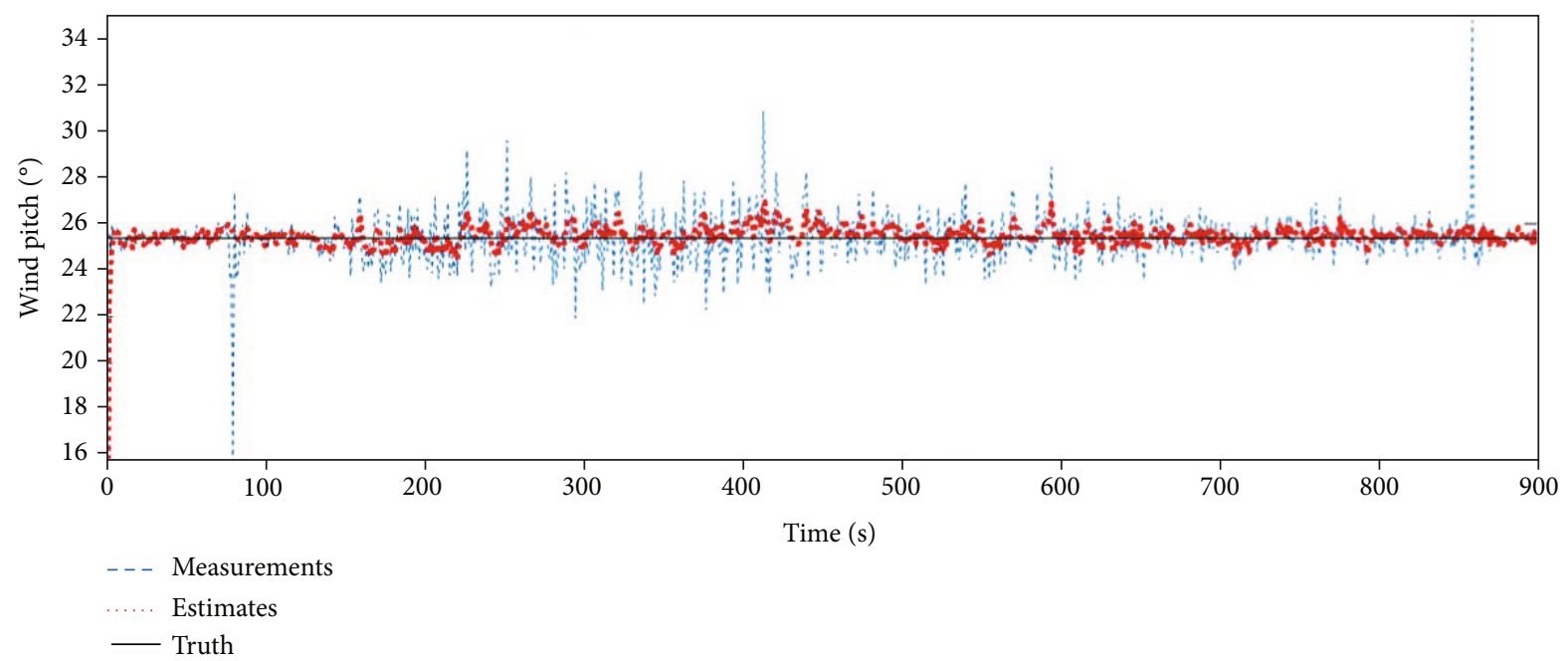

FIgURE 11: Wind pitch measurements, estimates, and true values.

TABLE 3: Standard deviation of estimated and measured value of random wind speed.

\begin{tabular}{|c|c|c|c|c|c|c|}
\hline \multirow[b]{2}{*}{$\begin{array}{l}\text { Speed: } \mathrm{m} / \mathrm{s} \\
\text { Angle: }^{\circ}\end{array}$} & \multicolumn{2}{|c|}{ Group 1} & \multicolumn{2}{|c|}{ Group 2} & \multicolumn{2}{|c|}{ Group 3} \\
\hline & $\begin{array}{l}\text { Standard deviation } \\
\text { of measurements }\end{array}$ & $\begin{array}{c}\text { Standard } \\
\text { deviation of } \\
\text { estimations }\end{array}$ & $\begin{array}{l}\text { Standard deviation } \\
\text { of measurements }\end{array}$ & $\begin{array}{c}\text { Standard } \\
\text { deviation of } \\
\text { estimations }\end{array}$ & $\begin{array}{l}\text { Standard deviation } \\
\text { of measurements }\end{array}$ & $\begin{array}{c}\text { Standard } \\
\text { deviation of } \\
\text { estimations }\end{array}$ \\
\hline North & 4.62 & 0.51 & 1.42 & 0.50 & 1.71 & 0.50 \\
\hline East & 1.35 & 0.37 & 0.72 & 0.36 & 0.58 & 0.37 \\
\hline Down & 2.15 & 0.27 & 0.53 & 0.27 & 0.85 & 0.26 \\
\hline Resultant & 5.23 & 0.60 & 1.46 & 0.59 & 1.93 & 0.59 \\
\hline Azimuth & 1.35 & 0.73 & 1.41 & 0.73 & 1.32 & 0.75 \\
\hline Pitch & 1.09 & 0.88 & 1.23 & 0.85 & 0.95 & 0.87 \\
\hline
\end{tabular}

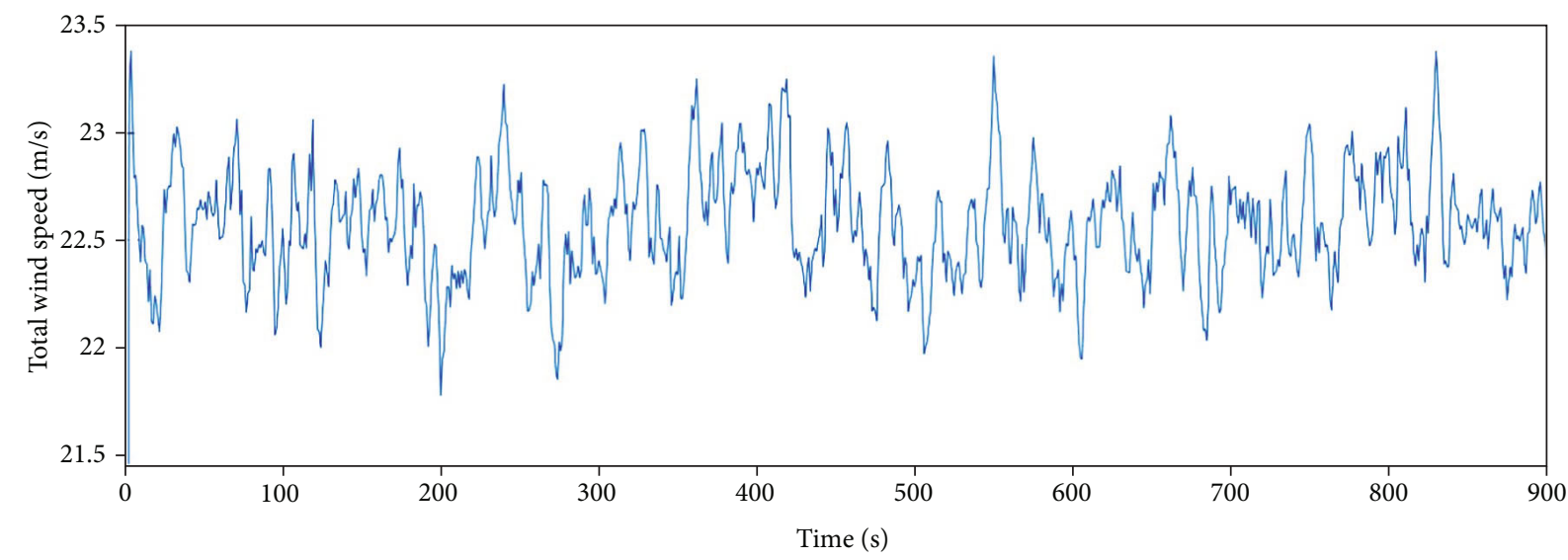

FIGURE 12: Multifrequency random wind speed.

in Figure 8) can be acquired. The standard deviations of the wind direction error of the proposed method are $1.73^{\circ}$ and $1.32^{\circ}$, respectively, while they are $4.70^{\circ}$ and $3.28^{\circ}$ for raw wind speed scenario.

In order to verify the reliability of the proposed method, we have carried out more than 1000 simulations and the statistical results are shown in Table 2.
Obviously, compared with the directly measured values, the accuracy of the estimated values is improved by nearly two times.

In order to further demonstrate the effectiveness of the proposed method, we also carried out the simulations with randomly changing wind speed. The true wind gust fields are modeled using a frozen Dryden turbulence mode [31]. 

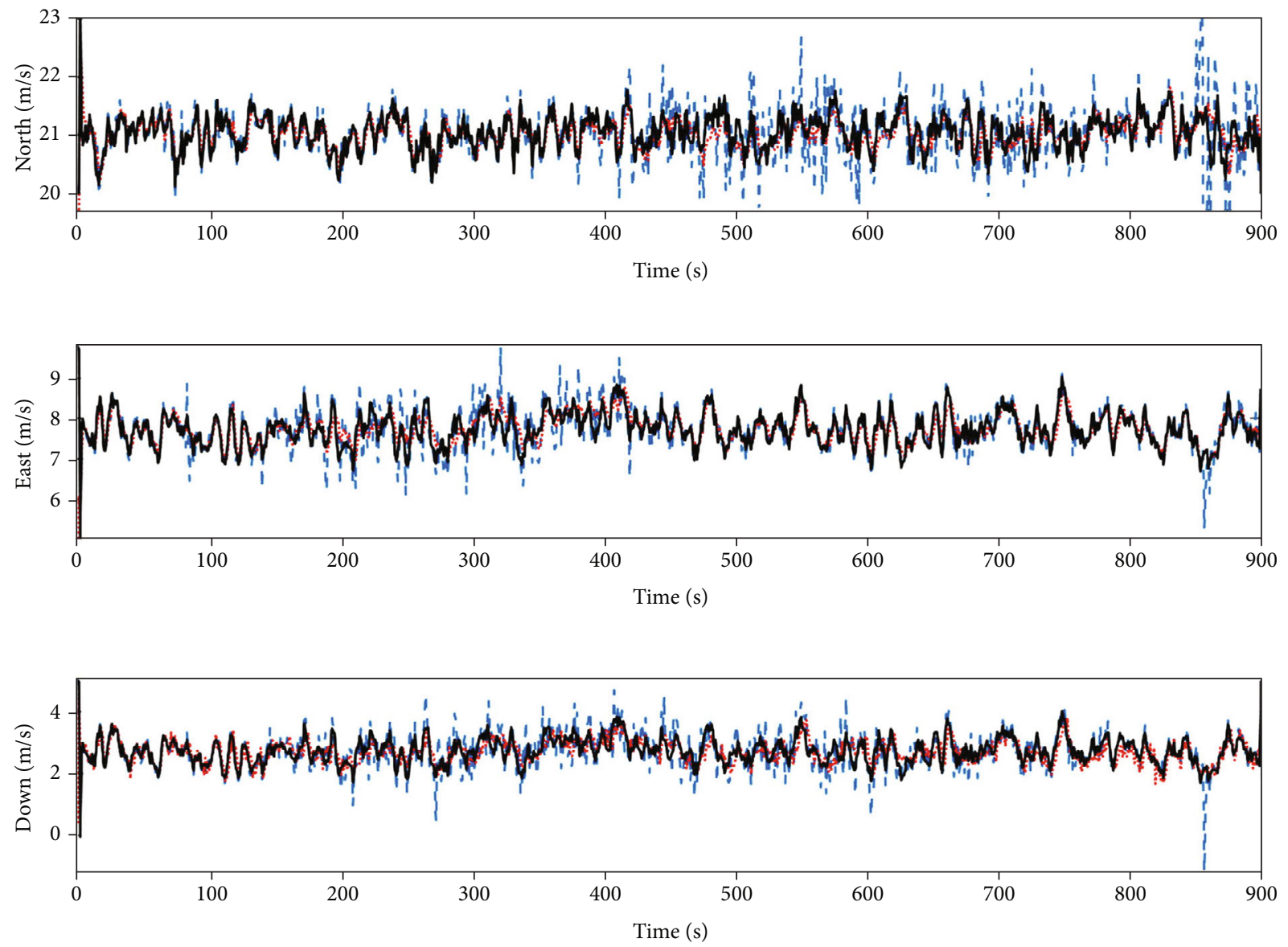

- - Measurements

Estimates

Truth

FIGURE 13: Multifrequency random wind speed measurements, estimates, and true values.

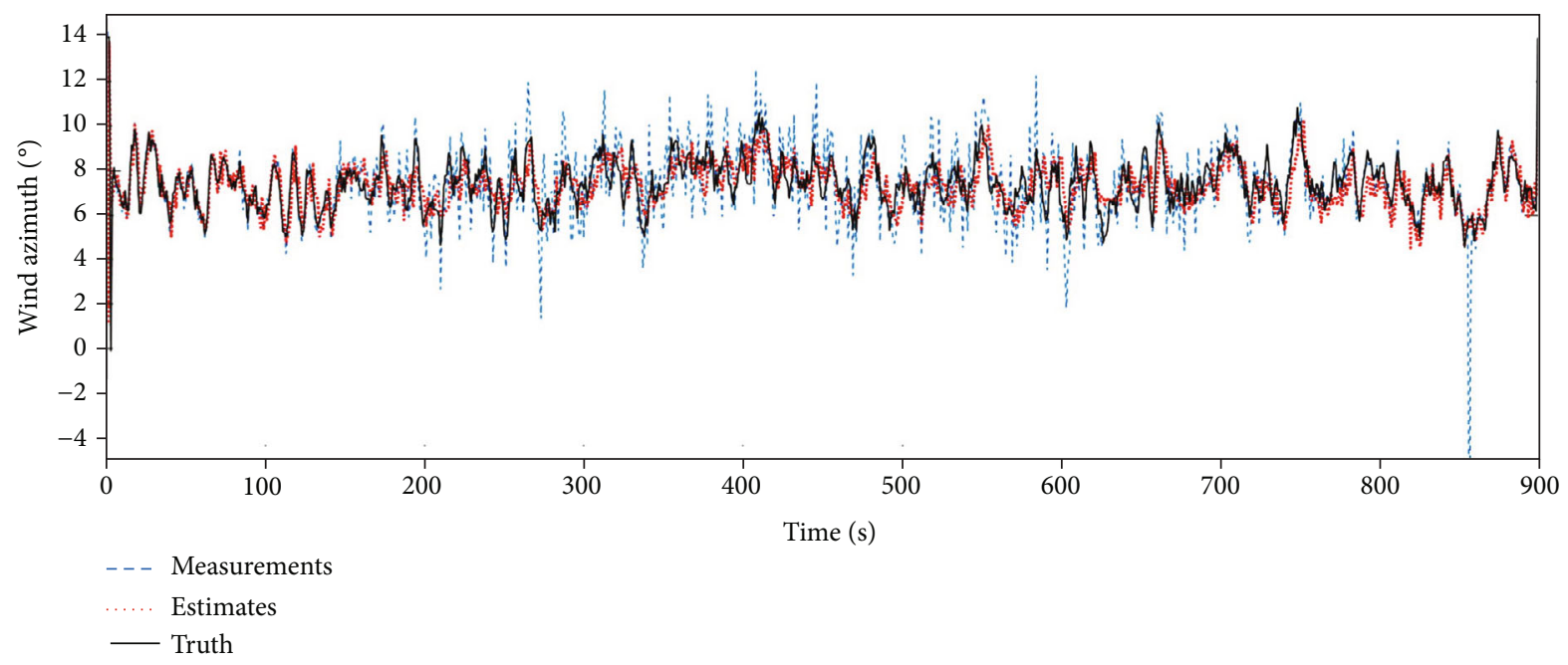

FIGURE 14: Multifrequency random wind azimuth measurements, estimates, and true values. 


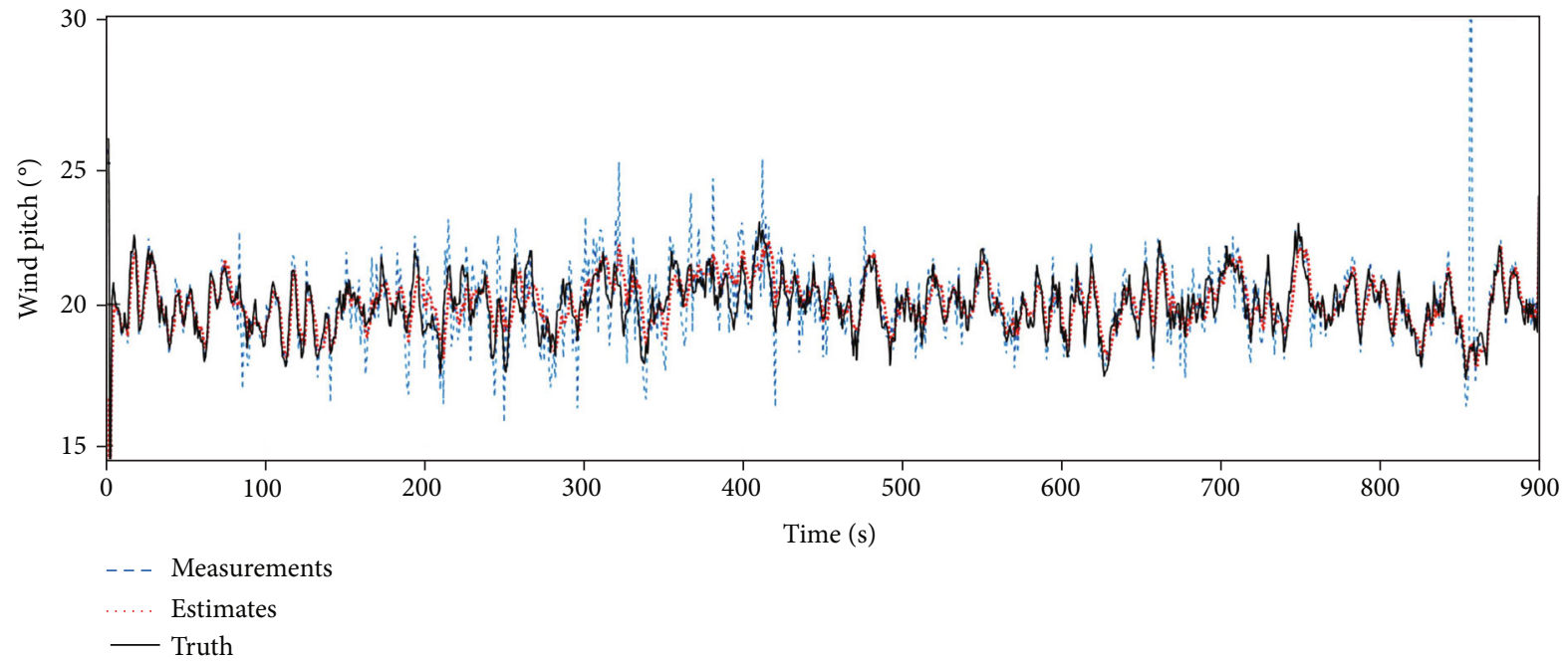

FIGURE 15: Multifrequency random wind pitch measurements, estimates, and true values.

TABLE 4: Standard deviation of estimated and measured value of multifrequency random wind speed.

\begin{tabular}{|c|c|c|c|c|c|c|}
\hline \multirow[b]{2}{*}{$\begin{array}{l}\text { Speed: m/s } \\
\text { Angle: }\end{array}$} & \multicolumn{2}{|c|}{ Group 1} & \multicolumn{2}{|c|}{ Group 2} & \multicolumn{2}{|c|}{ Group 3} \\
\hline & $\begin{array}{l}\text { Standard deviation } \\
\text { of measurements }\end{array}$ & $\begin{array}{c}\text { Standard } \\
\text { deviation of } \\
\text { estimations }\end{array}$ & $\begin{array}{l}\text { Standard deviation } \\
\text { of measurements }\end{array}$ & $\begin{array}{c}\text { Standard } \\
\text { deviation of } \\
\text { estimations }\end{array}$ & $\begin{array}{l}\text { Standard deviation } \\
\text { of measurements }\end{array}$ & $\begin{array}{c}\text { Standard } \\
\text { deviation of } \\
\text { estimations }\end{array}$ \\
\hline North & 0.68 & 0.23 & 0.82 & 0.25 & 0.64 & 0.24 \\
\hline East & 0.63 & 0.44 & 0.57 & 0.39 & 0.52 & 0.40 \\
\hline Down & 0.76 & 0.33 & 0.63 & 0.34 & 0.59 & 0.34 \\
\hline Resultant & 0.70 & 0.28 & 0.82 & 0.29 & 0.65 & 0.27 \\
\hline Azimuth & 1.86 & 0.91 & 1.74 & 0.92 & 1.59 & 0.92 \\
\hline Pitch & 1.55 & 1.08 & 1.65 & 0.95 & 1.32 & 0.94 \\
\hline
\end{tabular}

Air mass movement is expressed as a sum of sinusoids:

$$
w_{(\cdot)}=w_{(\cdot), 0}+\sum_{n=1}^{N} a_{(\cdot), n} \sin \left(\Omega_{(\cdot), n} s+\phi_{(\cdot), n}\right),
$$

where $(\cdot)$ represents the gust component and $s$ is motion along the flight path. Random values of $\phi_{(\cdot), n}$ simulate the random process, and the choice of coefficients $a_{(\cdot), n}$ defines the power spectral density.

The simulation results are shown in Figure 9. The standard deviations of the wind speed error of the proposed method are $0.50 \mathrm{~m} / \mathrm{s}, 0.36 \mathrm{~m} / \mathrm{s}$, and $0.27 \mathrm{~m} / \mathrm{s}$, respectively, while they are $1.42 \mathrm{~m} / \mathrm{s}, 0.72 \mathrm{~m} / \mathrm{s}$, and $0.53 \mathrm{~m} / \mathrm{s}$ for raw wind speed scenario.

Then, the wind azimuth (as shown in Figure 10) and pitch (as shown in Figure 11) are compared. The standard deviations of the wind direction error of the proposed method are $0.73^{\circ}$ and $0.85^{\circ}$, respectively, while they are $1.41^{\circ}$ and $1.23^{\circ}$ for raw wind speed scenario.

Similarly, more than 1000 simulations are carried out and the statistical results are shown in Table 3.

In order to realize the establishment of the Dryden model of random wind field from low to high frequency and considering the amount of calculation, $N=5$ in equation (23) is selected. The resultant velocity of the multifrequency random wind field generated by the simulation is shown in Figure 12.

The corresponding simulation results are shown in Figure 13. The standard deviations of the wind speed error of the proposed method are $0.25 \mathrm{~m} / \mathrm{s}, 0.35 \mathrm{~m} / \mathrm{s}$, and $0.27 \mathrm{~m} / \mathrm{s}$, respectively, while they are $0.69 \mathrm{~m} / \mathrm{s}, 0.55 \mathrm{~m} / \mathrm{s}$, and $0.61 \mathrm{~m} / \mathrm{s}$ for raw wind speed scenario.

The corresponding wind azimuth and pitch are shown in Figures 14 and 15. The standard deviations of the wind direction error of the proposed method are $0.83^{\circ}$ and $0.88^{\circ}$, respectively, while they are $1.65^{\circ}$ and $1.43^{\circ}$ for raw wind speed scenario.

Similarly, more than 1000 simulations are carried out and the statistical results are shown in Table 4 .

For all the set of simulations, the proposed wind speed estimation method provides wind speed with accuracy nearly two times better than raw measurements.

\section{Conclusions}

This paper proposes a novel online estimation method for the wind speed and direction around the fuselage, which can be used to improve the performance of on-time arrival 
in 4DT applications. The estimation method fuses INS, GNSS, and ADS in an UKF and provides great accuracy and robustness in nonlinearity conditions. The dynamic models of wind are established, and implementations of the UKF are detailed. Through flight simulations, the effectiveness of the method is verified by comparing with the traditional direct measurement method. Results demonstrate that the accuracy of wind speed and direction obtained by our method is nearly two times higher than the traditional direct measurement method.

\section{Data Availability}

The airplane design data used to support the findings of this study have not been made available because the project involves intellectual property rights.

\section{Conflicts of Interest}

The authors declare no conflict of interest.

\section{Acknowledgments}

This research was funded by the Beijing Natural Science Funds, grant number 4204103, and Aeronautical Science Foundation of China, grant number 2019ZC051009.

\section{References}

[1] J. W. Langelaan, N. Alley, and J. Neidhoefer, "Wind field estimation for small unmanned aerial vehicles," in Proc. AIAA Guidance, Navigation and Control Conference, pp. 10161030, Toronto, On, Canada, 2010.

[2] T. Yuan, Y. Bar-Shalom, P. Willett, and D. Hardiman, "Impact point prediction for thrusting projectiles in the presence of wind," IEEE Transactions on Aerospace and Electronic Systems, vol. 50, no. 1, pp. 102-119, 2014.

[3] P. B. S. Lissaman and C. K. Patel, "Neutral energy cycles for a vehicle in sinusoidal and turbulent vertical gusts," in 45th AIAA Aerospace Sciences Meeting and Exhibit, Reno, Nevada, 2007.

[4] Y. C. Qi and Y. J. Zhao, "Energy-efficient trajectories of unmanned aerial vehicles flying through thermals," Journal of Aerospace Engineering, vol. 18, no. 2, pp. 84-92, 2005.

[5] A. J. Calise and R. T. Rysdyk, "Nonlinear adaptive flight control using neural networks," IEEE Control Systems, vol. 18, no. 6, pp. 14-25, 1998.

[6] Y. Lei, Y. Y. Huang, and H. D. Wang, "Effects of wind disturbance on the aerodynamic performance of a quadrotor MAV during hovering," Journal of Sensors, vol. 1155, Article ID 6681716, 13 pages, 2021.

[7] M. Allen and V. Lin, "Guidance and control of an autonomous soaring UAV," NASA Dryden Flight Research Center, USA, NASA Technology Memory, TM-2007-214611, 2007.

[8] D. Edward, "Implementation details and flight test results of an autonomous soaring controller," in AIAA Guidance, Navigation and Control Conference, pp. 1-16, Honolulu, HI, USA, 2018.

[9] K. Andersson, I. Kaminer, V. Dobrokhodov, and V. Cichella, "Thermal centering control for autonomous soaring: stability analysis and flight test results," AIAA Journal of Guidance Control and Dynamics, vol. 49, no. 8, pp. 1292-1302, 2012.
[10] C. C. Lefas, "Real-time wind estimation and tracking with transponder downlinked airspeed and heading data," IEEE Transactions on Aerospace and Electronic Systems, vol. AES-23, no. 2, pp. 169-174, 1987.

[11] G. Campa, M. R. Napolitano, and M. L. Fravolini, "Simulation environment for machine vision based aerial refueling for UAVs," IEEE Transactions on Aerospace and Electronic Systems, vol. 45, no. 1, pp. 138-151, 2009.

[12] J. H. Lee, H. E. Sevil, A. Dogan, and D. Hullender, "Estimation of maneuvering aircraft states and time-varying wind with turbulence," in AIAA Guidance, Navigation, and Control Conference, Minneapolis, Minnesota, 2012.

[13] M. Kumon, I. Mizumoto, and Z. Iwai, "Wind estimation by unmanned air vehicle with delta wing," in IEEE International Conference on Robotics and Automation, pp. 1896-1901, Barcelona, Spain, 2005.

[14] R. E. Kalman and R. S. Bucy, "New results in linear filtering and prediction theory," Journal of Basic Engineering, vol. 83, no. 1, pp. 95-108, 1961.

[15] M. Kumon, I. Mizumoto, Z. Iwai, and M. Nagata, "Wind estimation by unmanned air vehicle with delta wing," IEEE International Conference on Robotics and Automation, vol. 2005, pp. 1896-1902, 2005.

[16] H. Long and S. J. Song, "Method of estimating angle-of-attack and sideslip angle based on data fusion," Second International Conference on Intelligent Computation Technology and Automation IEEE, vol. 1, pp. 641-644, 2009.

[17] C. Urrea and E. Agramonte, "Kalman filter: historical overview and review of its use in robotics 60 years after its creation," Journal of Sensors, vol. 2021, Article ID 9674015, 21 pages, 2021.

[18] M. Rhudy, T. Larrabee, H. Chao, Y. Gu, and M. R. Napolitano, "UAV attitude, heading, and wind estimation using GNSS/INS and an air data system," in AIAA Guidance Navigation and Control Conference, Boston, MA, 2013.

[19] A. Cho, J. Kim, S. Lee, and C. Kee, "Wind estimation and airspeed calibration using a UAV with a single-antenna GPS receiver and pitot tube," IEEE Transactions on Aerospace and Electronic Systems, vol. 47, no. 1, pp. 109-117, 2011.

[20] M. S. Grewal, L. R. Weill, and A. P. Andrew, Global Positioning Systems, Inertial Navigation and Integration, Wiley, New York, NY, USA, 2nd Ed. edition, 2007.

[21] J. H. Ryu, G. Gankhuyag, and K. T. Chong, "Navigation system heading and position accuracy improvement through GPS and INS data fusion," Journal of Sensors, vol. 2016, Article ID 7942963, 6 pages, 2016.

[22] S. Julier and J. Uhlmann, "A new extension of the Kalman filter to nonlinear systems," Signal Processing, Sensor Fusion, and Target Recognition VI, vol. 3068, pp. 182-193, 1997.

[23] B. R. Taylor, "A full-envelope air data calibration and threedimensional wind estimation method using global outputerror optimization and flight-test techniques," in AIAA Atmospheric Flight Mechanics Conference, pp. 1-16, Minneapolis, MN, USA, 2012.

[24] J. Liu, Z. Wang, L. Zhang, and P. Walker, "Sideslip angle estimation of ground vehicles: a comparative study," IET Control Theory and Applications, vol. 14, no. 20, pp. 3490-3505, 2020.

[25] C. Wang, Z. Wang, L. Zhang, D. Cao, and D. G. Dorrell, “A vehicle rollover evaluation system based on enabling state and parameter estimation," IEEE Transactions on Industrial Informatics, vol. 99, 2020. 
[26] X. L. Ding, C. Wang, L. Zhang, and C. Wang, "Longitudinal vehicle speed estimation for four-wheel-independently-actuated electric vehicles based on multi-sensor fusion," IEEE Transactions on Vehicular Technology, vol. 69, no. 11, pp. 12797-12806, 2020.

[27] J. Roskam, Airplane Flight Dynamics and Automatic Flight Controls, Design analysis and Research Corporation, Lawrence, KS, USA, 2003.

[28] R. A. Robinson, D. Butterfield, D. Curtis, and T. Thompson, "Problems with pitots: issues with flow measurement in stacks," in Presented at the Stationary Source Sampling and Analysis for Air Pollutants Conference, Rohnert Park, CA, 2005.

[29] V. Klein and E. A. Mprelli, Aircraft System Identification: Theory and Practice, American Institute of Aeronautics and Astronautics, Inc., Reston, VA, 2006.

[30] A. M. P. De Leege, M. Mulder, and M. M. Van Paassen, "Novel method for wind estimation using automatic dependent surveillance-broadcast," Journal of Guidance, Control, and Dynamics, vol. 35, no. 2, pp. 648-653, 2012.

[31] T. M. Ichwanul Hakim and O. Arifianto, "Implementation of Dryden continuous turbulence model into simulink for LSA-02 flight test simulation," Journal of Physics: Conference Series, vol. 1005, no. 1, article 012017, 2018. 